\title{
Decline in hospitalization rates for herpes zoster in Italy (2003-2018): reduction in the burden of disease or changing of hospitalization criteria?
}

\author{
Emanuele Amodio ${ }^{1} \cdot$ Alessandro Marrella $^{1} \cdot$ Alessandra Casuccio $^{1} \cdot$ Francesco Vitale $^{1}$ \\ Accepted: 19 October 2021 \\ (c) The Author(s), under exclusive licence to Springer Nature Switzerland AG 2021
}

\begin{abstract}
Background Herpes Zoster (HZ) is a very demanding disease caused by the reactivation of latent Varicella Zoster Virus. The main aim of this study was to estimate the burden of the HZ hospitalizations in Italy from 2003 to 2018 evaluating temporal trends.

Methods Retrospective population-based study analyzing Hospital Discharge Records. Hospitalization records reporting the ICD-9 CM 053.X code in the principal diagnosis or in any of the five secondary diagnoses were considered as cases. Trends of hospitalization rates have been evaluated by Joinpoint analyses.

Results Overall, 99,036 patients were hospitalized with HZ in the 16-year period of the study, and 83,720 (84.5\%) of these patients were over 50 years. Hospitalization rate was 10.4 per 100,000 persons/year with a significant decreasing trend from 13.9 in 2003-2006 to 7.8 in 2015-2018 $(p<0.001)$. Hospitalization rates showed a 20-fold higher risk among subjects aged over 80 years and 11-fold higher risk among 70-79-year-old subjects with respect to those aged less than 50 years. Over time, a statistically significant increase was observed for the case fatality rate (from 1.2 to $1.7 \% ; p<0.001$ ) and the median length of stay (from 7 to 8 days; $p<0.001$ ).

Conclusions Zoster is a disease that causes hospitalization as relatively frequent complication and the observed reduced trend over time could be due to a restriction in hospitalization criteria instead of a reduced burden of disease. The decreasing trend should be carefully interpreted, since it could have an impact on promoting herpes zoster vaccination.
\end{abstract}

Keywords Herpes zoster · Hospitalization · Italy

\section{Introduction}

Herpes Zoster (HZ) is a disease caused by the reactivation of latent Varicella Zoster Virus (VZV). Primary infection from VZV usually occurs in childhood (chickenpox) but after the resolution, despite the acquired long term immunity both cell-mediated and humoral, the virus remains silent in the sensory nerve ganglia after the recovery. HZ disease is frequent in the elderly, and it can be associated with a physiological decrease of cell-mediated immunity [1]. In this sense, one major risk factor for development of $\mathrm{HZ}$ is

Emanuele Amodio

emanuele.amodio@unipa.it

1 Department of Health Promotion, Mother and Child Care, Internal Medicine and Medical Specialties, University of Palermo, Via Del Vespro 133, Palermo, Italy aging [2] although other possible causes of decreased cellular immunity could be trigger factors. The main clinical presentation of $\mathrm{HZ}$ is a painful maculopapular rash with a dermatomal distribution, generally unilateral. The most common localization of the rash is thoracic, followed by ophthalmic [3].

In $70-80 \%$ of cases it is preceded by prodromes consisting in non-specific symptoms, from itching to a burning sensation [1] that occurs 1-5 days before the rash. Moreover, patients with certain debilitating medical conditions such as diabetes, chronic obstructive pulmonary disease or other conditions that require immunosuppressive treatments are at major risk to develop HZ and complicated HZ [4].

The most common complication of $\mathrm{HZ}$, occurring in $10-20 \%$ of cases [5], is post-Herpetic Neuralgia (PHN) [6] that is a long-term dermatomal pain, lasting usually at least 90 days after the rash [4]. Once PHN has developed, current treatments offer little to low benefit to the patients and 
adverse effects are common [2], and the cost of treatment is also significant [7]. Other common complications can be ophthalmic and neurologic, besides seldom seen can be visceral dissemination, encephalitis or meningitis [8]. Overall, $\mathrm{HZ}$ is a potentially debilitating condition, that can considerably decrease the quality of life [9] in a similar way like congestive heart failure, myocardial infarction and clinical depression [10].

According to the previous considerations, it is important to increase the efforts for preventing the development of the disease considering that most of the adult population (95\%) in Europe has anti-VZV antibodies and thus they could be, at least theoretically, susceptible to a $\mathrm{HZ}$ reactivation [11]. It is estimated that the risk to develop $\mathrm{HZ}$ is equal to $10-30 \%$ during life with a remarkable increase in older age, reaching a $50 \%$ in people over 85 years [12] and an incidence of $\mathrm{HZ}$ in the general population around 3 and 4 per 1000 persons [13].

In Italy 157,000 new cases are estimated to occur every year, accounting for an annual incidence of 6.3/1000 person-year [11], higher than the incidence observed by other studies in other European states (4/1000 in France [14], $3.56 / 1000$ in UK [15], 3.3/1000 in Netherlands [16] and $2.26 / 1000$ in Germany) [17]. According to the previous considerations, the main aim of this study was to estimate the burden of the hospitalizations due to Herpes Zoster in Italy from 2003 to 2018 evaluating temporal trends, the associated co-morbidities, and the burden of PHN.

\section{Methods}

We have performed a retrospective population-based study analyzing Hospital Discharge Records (HDR) from all public and private Italian hospitals recorded by the New Healthcare Information System of the Italian Minister of Health, during a 16-year period ranging from 2003 to 2018.

HDRs contain personal information of the patients (such as age, sex, place of residence, education level), characteristics of the hospitalizations (such as admission and discharge dates, discharge status, in-hospital transfers) and clinical conditions of the patients (primary and up to 5 secondary diagnoses, diagnostic/therapeutic procedures) $[18,19]$.

We considered as case of HZ hospitalization each record reporting the ICD-9 CM 053.X code in the principal diagnosis or in any of the five secondary diagnoses. Moreover, PHN cases were identified by codes (053.12 and 053.13) [4, $12]$ in any of the primary or secondary diagnoses.

Population data were obtained from the Italian National Institute of Statistics (Demo ISTAT) [20] and were used to calculate hospitalization rates. Moreover, rates have been stratified by age ( $<1$ year, $1-5$ years, $6-14$ years, 15-24 years, 25-64 years and 65 or more years) and mean length of hospital stay was also calculated. Incidence rates were calculated per 100,000 persons by dividing HZ hospitalization cases by the population resident in the year of interest.

\section{Statistical analyses}

HZ hospitalization cases have been reported as absolute and relative frequencies. The length of hospital stay, and patients' age were summarized as median (interquartile range).

A Joinpoint model was used to evaluate the time trends of hospitalization rates, the direction and the intensity of the (linear) trend, and the average annual percent change (AAPC).

Trends of hospitalization rates attributable to herpes zoster over time were evaluated by the Chi-square test for linear trend. Analysis of variance (ANOVA) was used to test the significance of differences between mean age at hospitalization calculated over the different time periods.

All statistical analyses were carried out using the R Software (Version 3.6.1) and the packages "Segmented" and "Strucchange" were used for the joint-point analysis. A $p$ value $<0.05$ was considered as statistically significant.

\section{Results}

A total of 99,036 patients were hospitalized with $\mathrm{HZ}$ in the 16-year period of the study, and 83,720 (84.5\%) of these patients were over 50 years (Table 1). Overall, hospitalization rate was 10.4 per 100,000 persons/year with a significant decreasing trend (from 13.9 in 2003-2006 to 7.8 in 2015-2018; $p<0.001)$. Crude hospitalization rates were higher in females (11.1 vs. 9.6 in males) and a significant decreasing trend was observed in both sexes. The most frequent complications were neurological (22.9\% of all hospitalizations), ocular complications (13\%), PHN (7.8\%) and meningitis (1.5\%). Most patients were discharged at home (data not shown in table) and patients who died increased through years from 1.2 to $1.7 \%$ of hospitalized patients. Case fatality rates showed a significant decreasing trend from $0.16 / 100,000$ to $0.13 / 100,000(<0.001)$. As reported in Fig. 1A, hospitalization rates showed a significant reduction in all age groups, whereas the hospitalization risk in the different age groups (Fig. 1B) was steady over time with 20 -fold risk among subjects aged over 80 years and 11 -fold risk among 70-79-year-old subjects with respect to those aged less than 50 years.

In Table 2, AAPC calculated for different patient groups were reported. A statistically significant reduction was found for all categories. An AAPC of - 4.7\% (- 5.1\%, - 4.3\%) was found for overall hospitalization rates. 
Table 1 General characteristics of patients with Herpes Zoster hospitalized in Italy between 2003 and 2018

\begin{tabular}{|c|c|c|c|c|c|c|}
\hline & 2003-2018 & 2003-2006 & $2007-2010$ & 2011-2014 & 2015-2018 & $p$ value \\
\hline Total $N$ (rates*100,000) & $99,036(10.4)$ & $32,244(13.9)$ & $26,343(11.0)$ & $21,620(9.0)$ & $18,829(7.8)$ & $<0.001$ \\
\hline \multicolumn{7}{|l|}{ Sex } \\
\hline Male, $N($ rates $* 100,000)$ & $44,609(9.6)$ & $14,532(12.9)$ & $11,844(10.2)$ & $9739(8.4)$ & $8494(7.2)$ & $<0.001$ \\
\hline Female, $N($ rates $* 100,000)$ & $54,427(11.08)$ & $17,712(14.8)$ & $14,499(11.8)$ & $11,881(9.6)$ & $10,335(8.3)$ & $<0.001$ \\
\hline \multicolumn{7}{|l|}{ Age } \\
\hline Total, median (IQR) & $73(21)$ & $71(21)$ & $73(21)$ & $74(22)$ & $75(22)$ & $<0.001$ \\
\hline Male, median (IQR) & $71(22)$ & $69(23)$ & $71(23)$ & $72(22)$ & $73(22)$ & $<0.001$ \\
\hline Female, median (IQR) & $75(21)$ & $73(21)$ & $75(20)$ & $75(21)$ & $76(20)$ & $<0.001$ \\
\hline \multicolumn{7}{|l|}{ Hospital stay } \\
\hline Day, median (IQR) & $8(8)$ & $7(7)$ & $8(8)$ & $8(9)$ & $8(9)$ & $<0.001$ \\
\hline \multicolumn{7}{|l|}{ Zoster as primary diagnosis } \\
\hline Rates * 100,000 & 4.8 & 7.28 & 5.17 & 3.86 & 3.16 & $<0.001$ \\
\hline$N(\%)$ & $46,205(46.6)$ & $16,921(52.5)$ & $12,361(46.9)$ & $9275(42.9)$ & $7648(40.6)$ & \\
\hline \multicolumn{7}{|l|}{ PHN complications } \\
\hline Rates * 100,000 & 0.81 & 1.0 & 0.9 & 0.7 & 0.6 & $<0.001$ \\
\hline$N(\%)$ & $7711(7.8)$ & $2376(7.4)$ & $2078(7.9)$ & $1763(8.2)$ & $1494(7.9)$ & \\
\hline \multicolumn{7}{|l|}{ Ocular complications } \\
\hline Rates $* 100,000$ & 1.35 & 2.0 & 1.4 & 1.1 & 0.9 & $<0.001$ \\
\hline$N(\%)$ & $12,881(13)$ & $4685(14.5)$ & $3426(13)$ & $2543(11.8)$ & $2227(11.8)$ & \\
\hline \multicolumn{7}{|l|}{ Neurological complications } \\
\hline Rates * 100,000 & 2.37 & 3.1 & 2.6 & 2.1 & 1.8 & $<0.001$ \\
\hline$N(\%)$ & $22,650(22.9)$ & $7161(22.2)$ & $6119(23.2)$ & $5124(23.7)$ & $4246(22.5)$ & \\
\hline \multicolumn{7}{|l|}{ Meningitis complications } \\
\hline Rates $* 100,000$ & 0.16 & 0.19 & 0.17 & 0.13 & 0.13 & $<0.001$ \\
\hline$N(\%)$ & $14,98(1.5)$ & $446(1.4)$ & $412(1.6)$ & $322(1.5)$ & $318(1.7)$ & \\
\hline \multicolumn{7}{|l|}{ Death } \\
\hline Rates $* 100,000$ & 0.15 & 0.16 & 0.16 & 0.15 & 0.13 & $<0.001$ \\
\hline$N(\%)$ & $1435(1.4)$ & $389(1.2)$ & $381(1.4)$ & $352(1.6)$ & $313(1.7)$ & \\
\hline
\end{tabular}

\section{Discussion}

This study aimed to describe the epidemiology of HZ hospitalizations in Italy during a 16-year period, paying particular attention to the trend of the disease. Our results suggest that during the entire observation period herpes zoster represented an important cause of morbidity requiring hospitalization in about 11 per 100,000 subjects per year. Our hospitalization incidence rate is quite similar to those reported in other European Countries (England 8.8/100,000 [21], Germany 9.60/100,000 [22], Denmark 13.1/100,000 [23], Spain 13.44/100,000 [24]) and it is included in the range from 2 to $25 / 100,000$ person-years observed by other researchers $[25,26]$.

However, as already reported, the hospitalization rates can significantly vary according to sex and age. A higher incidence was found in females, as confirmed by other studies $[21,25,27]$ and although herpes zoster is not a gender specific disease, a very plausible explanation of this disparity could reflect the higher longevity of females [20].
Considering age as risk factor, we have observed that the disease burden, as expected [25], was concentrated in people aged 50 years or older. In particular, according to the reported hospitalization rates, very old subjects can have a risk as high as 11 -fold risk (in those aged 70-79 years) up to 20-fold risk (in subjects aged over 79 years). Accordingly, these age groups should be considered as priority groups for herpes zoster vaccination to prevent zoster infection or, in vaccinated subjects with breakthrough infections, reduce the magnitude or frequency of symptoms caused by zoster, including postzoster neuralgia. However, age is not the only risk factor to be considered and it should be noted that more than half of hospitalizations occurred in patients with other co-morbidities as diabetes, chronic pulmonary disease, congestive heart failure or cancer. In these cases, herpes zoster has probably acted as triggering factor with respect to pre-existent co-morbidities. The fact that patients are commonly very frail is confirmed by evaluating the average hospital stay that in our study is quite long being about 
Fig. 1 Hospitalization rates due to Herpes Zoster in Italy from 2003 to 2018 stratified by agegroup and period (1A) and overtime relative risk of hospitalization compared to $0-49$ age class hospitalization rates (1B)
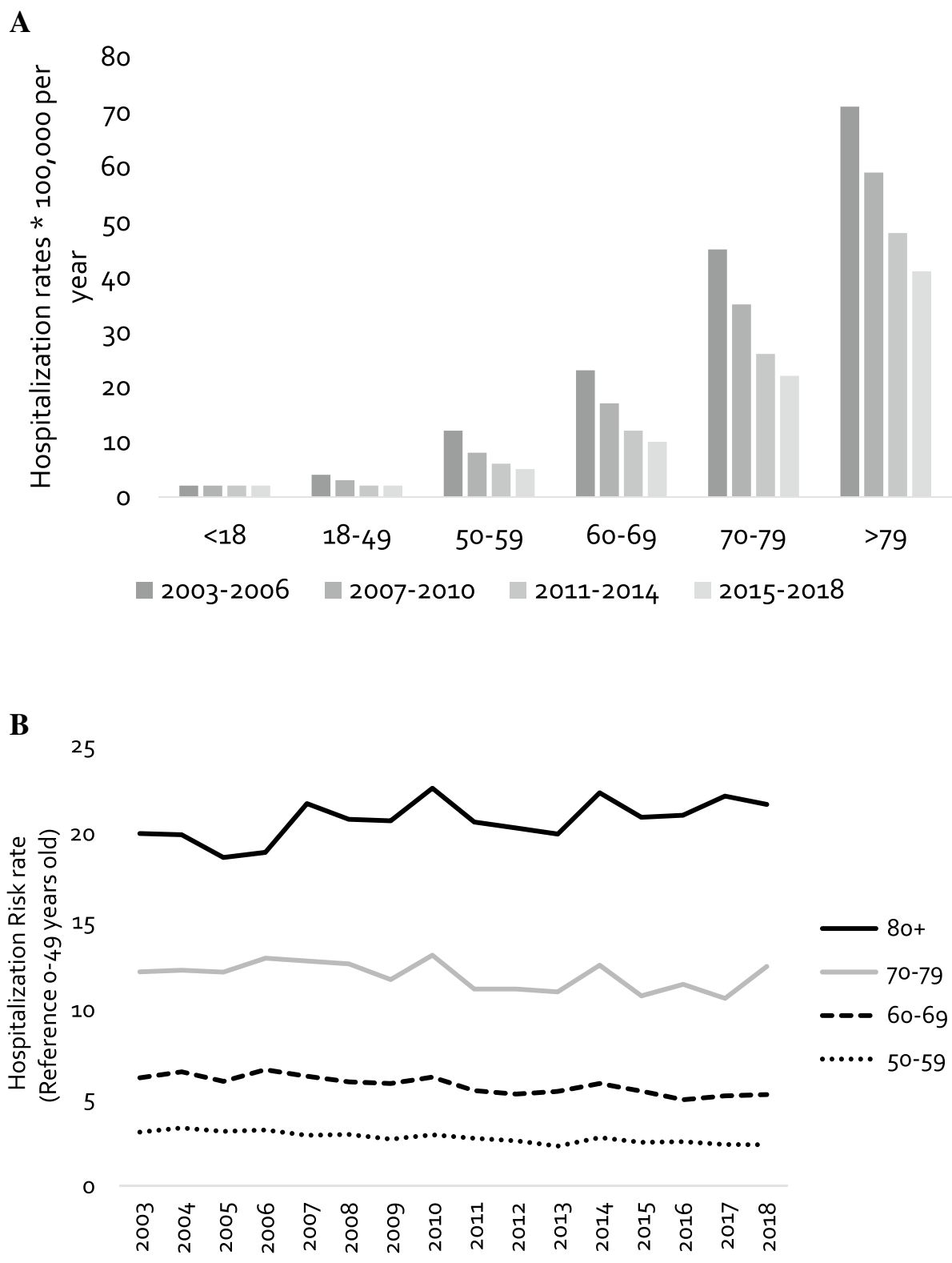

8 days. Our finding is consistent with the international literature (9.3 days in Portugal [28], 10 days in Spain [24] 6.2 in Denmark [23]) and it suggests that, if length of stay can be considered as a proxy measure for determining disease severity, thus hospitalizations due to herpes zoster can be long and very expensive.

However, there is a point that should be discussed with more attention. We have found a decreasing trend for hospitalization rates and this trend was confirmed in almost all subgroups (e.g., male and females, young and old subjects, etc.). The average percentage reduction in herpes zoster hospitalization was $-4.7 \%$ per year although some significant differences were found between groups. To our knowledge in Italy only another study calculated AAPC for HZ hospitalizations and found a reduction from 2001 to 2013 on
HZ-related hospitalizations of $-5.3 \%$, quite similar to that we have observed also in the following years [12].

What are the causal reasons besides a such decreasing trend is not easy to evaluate. However, there are some considerations that can be used for explaining some possible scenarios. The first point is that from 2003 to 2018, in Italy hospitalizations for any causa decreased from 12.8 to 8.7 millions per year (overall reduction - 32\%) [29]. This decrease was due to a general reduction in the number of hospital beds available in Italy between 2007 and 2018 [30, $31]$. However, the relative reduction observed for hospitalizations due to herpes zoster (overall reduction - 46.5\%) was quite higher than that observed for all hospitalizations. Some findings could help us to understand if there was or not a real reduction of the impact of the disease. 
Table 2 Joinpoint analysis and average annual percentage change (AAPC) stratified for different characteristic of the hospitalized patients

Overall AAPC (95\% CI)

\begin{tabular}{ll}
\hline Sex & \\
Male & $-4.7 \%(-5.13 \% ;-4.23 \%)^{\wedge}$ \\
Female & $-4.7 \%(-5.1 \% ;-4.3 \%)^{\wedge}$ \\
Total & $-4.7 \%(-5.1 \% ;-4.3 \%)^{\wedge}$ \\
Complicated cases & $-4.2 \%(-4.7 \% ;-3.7 \%)^{\wedge}$ \\
Only primary diagnosis & $-6.7 \%(-7.3 \% ;-6.1 \%)^{\wedge}$ \\
Only secondary diagnosis & $-2.9 \%(-3.1 \% ;-2.7 \%)^{\wedge}$ \\
PHN & $-4.1 \%(-4.8 \% ;-3.5 \%)^{\wedge}$ \\
Ocular complications & $-6.4 \%(-7.3 \% ;-5.5 \%)^{\wedge}$ \\
Neurological complications & $-4.5 \%(-4.9 \% ;-4.1 \%)^{\wedge}$ \\
Meningitis & $-3.1 \%(-4.5 \% ;-1.6 \%)^{\wedge}$ \\
\hline
\end{tabular}

${ }^{\wedge}$ Statistically significant trend

In this sense, the mean severity of the disease in hospitalized patients had a small but not negligible increase as suggested by mean hospital stay (about +1 day from 2003 to 2018$)$ and case fatality rate $(+0.5 \%)$. In addition, mean age of hospitalized patients increased over time ( +4 years) as well as the relative risk of hospitalization in the elderly with respect to $<50$-year-old subjects.

It is also true that we cannot exclude that some other factors could be involved in the observed decrease in herpes zoster hospitalization rates. One of these factors could be, at least theoretically, herpes zoster vaccination. However, in our opinion vaccination could have had only a relative impact, since it has been officially introduced in the Italian Immunization Plan only in 2017 and in the previous years the coverage could be considered very low or negligible. On the other hands, it should be evaluated that the decreasing trend deserves some inferences also in relationship to a possible role of paediatric varicella vaccination. In particular, some studies postulated an increase in herpes zoster incidence in the general population after the introduction of childhood vaccination under assumption of reduced exogenous boosting [32]. Although the paediatric varicella vaccination in Italy was introduced only in the recent years (from 2003 to 2015), our data seem to exclude this contribute [33-35].

Finally, our study has some possible limitations that are also attributable to the reliability of hospital-based data sets. This last depends on the quality of the discharge report, and we cannot exclude some variation of codification process between different regions or in different years. Moreover, zoster is usually a disease that is managed on an outpatient basis and, thus, hospitalizations could be not a good indicator of the disease burden trend in the general population.
Despite of these possible limits, our study suggests that Zoster is still a disease causing hospitalization as relatively frequent complication and that the reduced trend over time that we have found could be due to other factors instead of a reduced burden of disease. In this sense, this downward trend must not in any way limit Public Health efforts in promoting herpes zoster vaccination especially in the elderly and in subjects with other co-morbidities who continue to be at a higher risk for severe sequelae due to the virus reactivation.

Acknowledgements The Authors are fully obliged the Italian Ministry of Health that collected and provided hospitalization data.

Funding No funding.

Availability of data and materials (data transparency) Data will be available upon motivated request to the first author.

\section{Declarations}

Conflict of interest Authors do not have competing interests or conflict of interest to declare.

Ethical approval An ethical approval is not formally required in Italy, since the study analyzes anonymous data collected by the Italian Health Minister.

Informed consent According to the Italian Law, an informed consent was not required for this study as data were anonymous and collection was retrospective.

Consent to participate Not required according to the Italian law.

Consent for publication Not required according to the Italian law.

\section{References}

1. Johnson R, McElhaney J, Pedalino B et al (2007) Prevention of herpes zoster and its painful and debilitating complications. Int $\mathbf{J}$ Infect Dis Suppl 2:S43-S48

2. Johnson RW (2010) Herpes zoster and postherpetic neuralgia. Expert Rev Vaccine 9:21-26

3. Opstelten W, Zaal MJ (2005) Managing ophthalmic herpes zoster in primary care. BMJ 331:147-151

4. Cocchio S, Baldovin T, Furlan P et al (2019) Cross-sectional study on hospitalizations related to herpes zoster in an Italian region, 2008-2016. Aging Clin Exp Res 31:145-150

5. Opstelten W, Mauritz JW, de Wit NJ et al (2002) Herpes zoster and postherpetic neuralgia: incidence and risk indicators using a general practice research database. Fam Pract 19:471-475

6. Centers for Disease Control and Prevention (2021) Available at https://www.cdc.gov/shingles/index.html. Accessed 3 Mar 2021

7. White RR, Lenhart G, Singhal PK et al (2009) Incremental 1 -year medical resource utilization and costs for patients with herpes zoster from a set of US health plans. Pharmacoeconomics 27:781-792 
8. Gnann JW Jr (2002) Varicella-zoster virus: atypical presentations and unusual complications. J Infect Dis 186:S91-S98

9. Lydick E, Epstein RS, Himmelberger D et al (1995) Herpes zoster and quality of life: a self-limited disease with severe impact. Neurology 45:S52-S53

10. McElhaney JE (2010) Herpes zoster: a common disease that can have a devastating impact on patients' quality of life. Expert Rev Vaccines 9:27-30

11. Gabutti G, Franco E, Bonanni P et al (2015) Reducing the burden of Herpes Zoster in Italy. Hum Vaccin Immunother 11:101-107

12. Valente N, Cocchio S, Stefanati A et al (2017) Temporal trends in herpes zoster-related hospitalizations in Italy, 2001-2013: differences between regions that have or have not implemented varicella vaccination. Aging Clin Exp Res 29:771-779

13. Stein AN, Britt H, Harrison C et al (2009) Herpes zoster burden of illness and health care resource utilisation in the Australian population aged 50 years and older. Vaccine 27:520-529

14. Chidiac C, Bruxelle J, Daures JP et al (2001) Characteristics of patients with herpes zoster on presentation to practitioners in France. Clin Infect Dis 33:62-69

15. Brisson M, Edmunds WJ (2003) Epidemiology of Varicella-Zoster Virus in England and Wales. J Med Virol 70:S9-S14

16. de Melker H, Berbers G, Hahné S et al (2006) The epidemiology of varicella and herpes zoster in The Netherlands: implications for varicella zoster virus vaccination. Vaccine 24:3946-3952

17. Paul E, Thiel T (1996) Zur Epidemiologie der Varizella-ZosterInfektion Ergebnisse einer prospektiven Erhebung im Landkreis Ansbach [Epidemiology of varicella zoster infection. Results of a prospective study in the Ansbach area]. Hautarzt 47:604-609

18. Gialloreti LE, Merito M, Pezzotti P et al (2010) Epidemiology and economic burden of herpes zoster and post-herpetic neuralgia in Italy: a retrospective, population-based study. BMC Infect Dis 10:230

19. La scheda di dimissione ospedaliera (SDO). www.salute.gov.it. [Online] http://www.salute.gov.it/portale/temi/p2_6.jsp?lingua= italiano\&id $=1232 \&$ area $=$ ricoveriOspedalieri\&menu $=$ vuoto. Accessed 3 Nov 2020

20. ISTAT. Available at http://demo.istat.it/. Accessed 03 Nov 2019

21. Hobbelen PH, Stowe J, Amirthalingam G et al (2016) The Burden of Hospitalisation for Varicella and Herpes Zoster in England from 2004 to 2013. J Infect 73:241-253

22. Ultsch B, Siedler A, Rieck T et al (2011) Herpes zoster in Germany: quantifying the burden of disease. BMC Infect Dis 11:173

23. Schmidt SAJ, Kahlert J, Vestergaard M et al (2016) Hospitalbased herpes zoster diagnoses in Denmark: rate, patient characteristics, and all-cause mortality. BMC Infect Dis 16:99

24. Gil A, Gil R, Alvaro A et al (2009) Burden of Herpes Zoster Requiring Hospitalization in Spain during a Seven-Year Period (1998-2004). BMC Infect Dis 9:55. https://doi.org/10.1186/1471
25. Kawai K, Gebremeskel BG, Acosta CJ (2014) systematic review of incidence and complications of herpes zoster: towards a global perspective. BMJ Open 4:e004833. https://doi.org/10.1136/bmjop en-2014-004833

26. Di Legami V, Gianino MM, Ciofi degli Atti M et al (2007) Epidemiology and costs of herpes zoster: background data to estimate the impact of vaccination. Vaccine 25:7598-7604. https://doi.org/ 10.1016/j.vaccine.2007.07.049

27. Salleras L, Salleras M, Salvador $P$ et al (2015) Herpes zoster and postherpetic neuralgia in Catalonia (Spain). Hum Vaccin Immunother 11:178-184

28. Mesquita M, Froes F (2013) Hospital Admissions for Herpes Zoster in Portugal between 2000 and 2010. Acta Med Port 26:531-536

29. Italian Health Ministry. Available at http://www.salute.gov.it/porta le/temi/p2_6.jsp?lingua $=$ italiano $\& i d=5458 \&$ area $=$ ricoveriOs pedalieri\&menu=vuoto. Accessed 20 Feb 2020. Last Accessed 21 Jan 2021

30. Pecoraro F, Clemente F, Luzi D (2020) The efficiency in the ordinary hospital bed management in Italy: an in-depth analysis of intensive care unit in the areas affected by COVID-19 before the outbreak. PLoS ONE 15:e0239249

31. Marino D, Quattrone G (2019) A proposal for a new index to evaluate hospital resource allocation: the case of Italian NHS rationalisation. Eur Res Manag Bus Econ 25:23-29. https://doi. org/10.1016/j.iedeen.2018.10.001

32. Brisson M, Edmunds WJ, Gay NJ et al (2000) Modelling the impact of immunization on the epidemiology of varicella zoster virus. Epidemiol Infect 125:651-669

33. Amodio E, Casuccio A, Tramuto F et al (2020) Varicella vaccination as useful strategy for reducing the risk of varicella-related hospitalizations in both vaccinated and unvaccinated cohorts (Italy, 2003-2018). Vaccine 38:5601-5606

34. Holl K, Sauboin C, Amodio E et al (2016) Coverage, efficacy or dosing interval: Which factor predominantly influences the impact of routine childhood vaccination for the prevention of varicella? A model-based study for Italy. BMC Public Health 16:1103

35. Amodio E, Tramuto F, Cracchiolo M et al (2015) The impact of ten years of infant universal Varicella vaccination in Sicily, Italy (2003-2012). Hum Vaccin Immunother 11:236-239

Publisher's Note Springer Nature remains neutral with regard to jurisdictional claims in published maps and institutional affiliations. 